\title{
Vulnerabilidad y prácticas de información: experiencias de migrantes latinos (indocumentados) en EE.UU.**
}

\author{
Vulnerability and Information practices: \\ experiences of (undocumented) Latino migrants in the U.S.
}

Vulnerabilidade e práticas de informação: experiências de migrantes latinos (não documentados) nos Estados Unidos

\footnotetext{
* Profesor Asociado, Escuela Información de la Universidad de Washington, especializado en temas de usos comunitarios de las tecnologías de información, bibliotecas públicas, y evaluación de impactos. Correo electrónico: rgomez@uw.edu

** Artículo resultado de la investigación Proyecto Fotohistorias: Fotografia participativa y experiencias de migración, 2013-2016, con financiación parcial de Royalty Research Fund de Universidad de Washington. Una versión anterior de este artículo en inglés aparece en Electronic Journal of Information Systems in Developing Countries EJISDC, 75(1). Traducción del inglés: Camila Gomez-Wills. Artículo de investigación recibido el 23/05/2016 y aceptado el 19/08/2016.
} 


\section{Cómo citar}

GómEz, R. (2016). Vulnerabilidad y prácticas de información: experiencias de migrantes latinos (indocumentados) en EE.UU.

Revista CS, no. 20, pp. 93-121. Cali, Colombia: Facultad de Derecho y Ciencias Sociales, Universidad Icesi.

DOI: http://dx.doi.org/10.18046/recs.i20.2211 


\section{Resumen}

Abstract

Resumo

Este artículo explora las prácticas de información (búsqueda, uso y distribución de la información) de los migrantes latinos, en particular de aquellos que están indocumentados en la frontera entre México y EE.UU., y en Seattle, Washington. En estos contextos se generan prácticas de información diferentes. En la frontera encontramos más prácticas de pobreza de información tipo "pequeño mundo", las cuales se van ampliando y consolidando a medida que se fortalece el sentido de pertenencia después de pasar más tiempo establecidos en EE.UU. Sin embargo, la vulnerabilidad y la transitoriedad se mantienen, ante el riesgo permanente de deportación. Los hallazgos del estudio en comunidades colombianas se presentan en otro artículo complementario en el siguiente número de esta revista. A través de la fotografía participativa y entrevistas no estructuradas, exploramos las vivencias y las prácticas de información de comunidades marginadas, y las relacionamos con cómo vivencian la transitoriedad a lo largo de las distintas etapas de la experiencia migratoria. También discutimos cómo las etapas de la migración pueden no ser suficientes para dar cuenta de los constantes cambios e iteraciones en las experiencias de los migrantes que estudiamos.

\section{PALABRAS CLAVE:}

Migrantes latinos | indocumentados | prácticas de información | comportamientos de información | fotografía participativa

This paper explores the Information practices (search, use and distribution of information) by Latino migrants, in particular those who are undocumented, at the US-Mexico border and in Seattle, Washington. Different information practices emerge in these contexts. At the border, we find more information poverty practices of the "small world" type, and these slowly broaden and consolidate as the migrants' sense of belonging is strengthened after they live more time established in the US. Nonetheless, the vulnerability and impermanence remain, in the face of constant danger of deportation. The findings of a complementary study among communities in Colombia are presented in the next issue of this journal. Using participatory photography and unstructured interviews, we explore the experiences and the information practices among marginalized communities, and we relate them to how they 
experience impermanence during different stages of the migration experience. We also discuss how the migration stages may not be sufficient to account for the constant changes and iterations in the experiences of migrants in our study.

\section{KEYWORDS:}

Latino migrants | undocumented | information practices | information behavior | participatory photography

Este artigo explora as práticas de informação (pesquisa, uso e distribuição da informação) dos migrantes latinos, particularmente aqueles que estão em situação irregular na fronteira EUA-México, e em Seattle, Washington. Neste contexto geram-se práticas de informação diferentes. Na fronteira encontramos mais práticas de pobreza de informação tipo "pequeno mundo", as quais são ampliadas e consolidadas em quanto o sentimento de pertença se reforça após passar mais tempo estabelecidos nos EUA. Porém, a vulnerabilidade e transitoriedade permanecem, perante o risco constante de deportação. Os resultados do estudo em comunidades colombianas são apresentados em outro artigo complementário na próxima edição desta revista. Através da fotografia participativa e entrevistas não estruturadas, exploramos as experiências e práticas de informação de comunidades marginalizadas e as relacionamos com o jeito em que vivenciam a transitoriedade ao longo das diferentes fases da experiência de migração. Também discutimos como as etapas de migração podem não ser suficientes para explicar as constantes mudanças e iterações sobre as experiências dos migrantes estudados.

\section{PALAVRAS CHAVES:}

Migrantes latinos | não documentados | práticas de informação | comportamentos de informação | fotografia participativa 


\section{Introducción}

Aunque la migración interna es un fenómeno importante en muchos países, es frecuentemente conceptualizada como el movimiento de las personas a través fronteras internacionales. Algunos autores han llamado transmigración a esta forma de la experiencia migratoria internacional, aunque no sea esta la única forma de migrar que afecta las vidas humanas. "Los transmigrantes son inmigrantes cuyas vidas cotidianas dependen de múltiples y constantes redes de conexiones a través de fronteras internacionales, y cuyas identidades públicas se construyen en relación a más de un estado nación" (Schiller, Basch y Blanc, 1995).

Nuestro estudio explora importantes asuntos en relación a la migración transnacional en las experiencias de migrantes latinos (indocumentados) en la frontera entre México y EE.UU. y en Seattle, Washington. Para tener un punto de referencia y de comparación, también incluimos comunidades en los alrededores de Cali, Colombia (presentado en un artículo aparte en el próximo número de esta revista).

Múltiples autores han estudiado las prácticas de información, referidas a búsqueda, uso y distribución de información (Savolainen, 2008) de los migrantes (para un buen resumen, ver Caidi, Allard y Quirke, 2010). Muy pocos se han enfocado en los "excluidos" que se encuentran en uno de los polos del continuo de Nail: los que buscan asilo, los trabajadores migrantes, los sans papiers ${ }^{1} \mathrm{y}$ los migrantes irregulares o indocumentados, entre otros. Todos ellos viven al margen de la vida política y extremadamente marginalizados y excluidos de la sociedad dominante. Las prácticas de información de estos grupos de migrantes extremadamente marginalizados y excluidos han recibido poca atención en la literatura de las ciencias de la información y de los sistemas de información. Algunas excepciones e incursiones tempranas que vale la pena resaltar son los estudios sobre los servicios de bibliotecas para jornaleros (Jensen, 2002), los comportamientos de información de los trabajadores del sector agropecuario inmigrantes (Fisher et al., 2004) y un trabajo previo sobre los comportamientos de información de los jornaleros latinos o de habla hispana (Baron et al., 2013; Newell et al., 2016; Vannini et al., 2016), entre otros.

Desprovistos de derechos, e incluso desprovistos del derecho a tener derechos, los migrantes indocumentados son en nuestra época la expresión más clara de la privación consciente de derechos humanos básicos para la totalidad de un grupo humano. Al excluirlos de la legalidad, el Estado sitúa a los migrantes indocumentados por fuera de los límites de la ley, al mismo tiempo que les aplica leyes que los excluyen sistemáticamente. De acuerdo con el filósofo italiano Agamben (1998), esta dicotomía de estar adentro/ afuera de la ley es el estado de excepción en el que se legitima la violencia soberana que reduce al otro a la nuda vida, sin derecho político alguno. Sin embargo, el trabajo de

1. "Sin papeles". En francés en el original. 
los migrantes indocumentados, reducido a la nuda vida, es un elemento central de la economía estadounidense, dado que hacen el trabajo que otros no hacen, y lo hacen por menos dinero y en condiciones más peligrosas y precarias. Esto contribuye a bajar los precios y a subir las utilidades. El trabajo de los migrantes indocumentados es "esencial para el funcionamiento de la economía y para la comodidad de los ciudadanos. Aun así, el sistema es también fundamentalmente injusto. Al crear una fuerza laboral subordinada y sin estatus legal, estamos manteniendo un sistema de desigualdad legalizada" (Chomsky, 2014: 14). En este contexto, este documento busca contribuir a la pequeña pero creciente literatura sobre las prácticas de información de los migrantes indocumentados.

Caidi y sus colegas describen un continuo (a veces sobrepuesto) de etapas de asentamiento que ayudan a situar las prácticas de información de los migrantes:

(1) la etapa pre-migratoria (antes de que el individuo migre a su nuevo país; la información se recoge de fuentes formales como las publicaciones y sitios web de agencias gubernamentales, abogados o agencias especializadas en temas migratorios, así como también fuentes informales como la familia y amigos, blogs y listas de correo (2) la etapa inmediata (v.gr. la información sobre las necesidades básicas y la supervivencia tales como refugio, orientación en una nueva ciudad, formación en otro idioma); (3) la etapa intermedia (la información necesaria para tener acceso a sistemas e instituciones locales a nivel municipal que tienen información legal, sobre la vivienda, la salud, y los servicios de empleo; (4) la etapa de integración (en la medida en que los inmigrantes se acostumbran a su nuevo país, sus necesidades de información son más diversas y pueden llegar a estar relacionadas con el deseo de una mayor participación política en la esfera pública) (Caidi et al., 2010: 505).

Aunque el esquema es útil, se puede asumir que estas etapas son una progresión lineal que refleja la experiencia impermanente y transitoria de los migrantes indocumentados. Como complemento a las etapas de asentamiento de Caidi y sus colegas, construimos el Continuo de la Transitoriedad (Vannini et al., 2016), en el cual las variables para entender los comportamientos de información de los migrantes latinos en EE.UU. son la transitoriedad y la permanencia. En un extremo se ubica la experiencia efímera y transitoria de la migración, asociada al comportamiento de información caracterizado por la cuidadosa búsqueda de información en fuentes altamente confiables, y en el otro extremo, la experiencia (más) duradera de la migración, en la cual los migrantes tienen un comportamiento de información en el que proveen información para otros.

Este mapa conceptual de las etapas de adaptación y los comportamientos de información relacionados con la transitoriedad se enriquece con la noción de "pobreza de información" (Chatman, 1996) y de la identidad de las tecnologías de información (Carter y Grover, 2015) como lentes adicionales para entender los comportamientos de información de los migrantes indocumentados. 
FIGURA 1 | Continuo de la Transitoriedad (Vannini et al., 2016)

\begin{tabular}{|c|c|c|c|c|}
\hline Transience & $\begin{array}{l}\text { Transient } \\
\text { ephemeral }\end{array}$ & $\begin{array}{l}\text { Moderately } \\
\text { transient }\end{array}$ & $\begin{array}{l}\text { Moderately } \\
\text { enduring }\end{array}$ & Enduring \\
\hline Security & $\begin{array}{l}\text { No space for } \\
\text { advocacy and } \\
\text { activism }\end{array}$ & & & $\begin{array}{l}\text { Advocating for } \\
\text { themselves and } \\
\text { others }\end{array}$ \\
\hline $\begin{array}{l}\text { Information } \\
\text { behavior }\end{array}$ & $\begin{array}{l}\text { Careful seeker } \\
\text { of information, } \\
\text { trusted sources }\end{array}$ & & & $\begin{array}{l}\text { Providers of } \\
\text { information for } \\
\text { other }\end{array}$ \\
\hline
\end{tabular}

El resto del artículo presenta una breve reseña de la metodología de este estudio con fotografía participativa y los contextos de trabajo en la frontera y en Seattle, Washington, seguida de los principales hallazgos, en ese orden. Cerramos con las conclusiones del estudio.

\section{Métodos: Fotohistorias y fotografía participativa}

Este estudio usa la fotografía participativa como manera de recoger testimonios y experiencias de los participantes (Gómez \& Vannini, 2015; Yefimova et al., 2015) en un proceso de cuatro etapas: 1 ) colaboración con organizaciones locales para tener acceso a los participantes; 2) generación de imágenes tomadas por los participantes mismos; 3) conversación sobre las fotos a través de entrevistas abiertas hablando sobre qué ven en las fotos y cuál es su significado; y 4) análisis y diseminación a través de codificación abierta, identificación de temas, y preparación de exhibiciones y otros productos de diseminación. El uso de fotografía participativa permite entrar en niveles de profundidad e introspección que pueden ser difíciles de conseguir a través de entrevistas solamente, y complementa las palabras con imágenes evocativas que ayudan a dar cuenta de las experiencias de vida de los migrantes.

\section{Contextos para este estudio}

La frontera entre México y EE.UU. es la frontera terrestre más transitada del mundo, y también es la más patrullada por fuerzas de seguridad. De acuerdo con Pew, en los cinco meses entre octubre de 2013 y febrero de 2014, más de 21.0oo migrantes trataron de cruzar la frontera desde México (Pew, citado en COHA, sin fecha). Por otro lado, en 
2013, 438.421 migrantes no autorizados fueron deportados de EE.UU. (González Barrera y Krogstad, 2014). Cruzar la frontera como indocumentado no es fácil. Miles mueren cada año intentándolo y otros miles son aprehendidos. Nuestra área de estudio en Nogales, México hace parte del sector de Tucson de la frontera que, entre 1998 y 2013, tuvo el número más alto de aprehensiones de migrantes indocumentados y el número más alto de muertes. Se estima que entre 2010 y 2013 al menos 700 migrantes murieron solo en ese sector (Newell y Gómez, 2014). Izcara Palacios ha realizado importantes estudios que ayudan a entender las causas y expresiones de los migrantes en la frontera entre EE.UU. y México (Izcara Palacios, 2012, 2016a, b; Izcara Palacios \& Andrade Rubio, 2015), sin embargo no se enfocan en las prácticas de información de los migrantes.

A través de la fotografía participativa y las entrevistas con migrantes en Nogales, en la frontera entre México y EE.UU., exploramos la transitoriedad y la impermanencia de la noción de hogar tal y como es vivida por los migrantes indocumentados. Algunos de ellos acababan de ser deportados de EE.UU., y otros acababan de llegar a Nogales del sur de México u otros países de Centroamérica. Encontraron el albergue "El Comedor", de la Iniciativa Kino para la Frontera, donde pueden recibir comida, elementos básicos de cuidado personal, ropa y servicios tales como atención médica, llamadas y un lugar seguro para pasar el tiempo mientras deciden qué hacer. Llevan sus sueños y sus pertenencias en una bolsa plástica y generalmente no saben ni dónde dormirán esa noche, ni cuándo ni dónde será su siguiente comida. La información es crítica en este estado de la migración, pero también es peligrosa. Incluso actos tan sencillos como una llamada telefónica ponen a los migrantes en riesgo de extorsión y abuso (Newell y Gómez, 2014), lo cual hace que el trabajo de organizaciones dedicadas a la ayuda humanitaria y al apoyo de los migrantes, como la Iniciativa Kino para la Frontera, sea más importante que nunca para proteger los derechos humanos básicos y la dignidad de los migrantes (indocumentados).

Para explorar la experiencia del migrante desde la perspectiva de los migrantes latinos (indocumentados) ya establecidos en EE.UU., usamos la fotografía participativa y entrevistas con jornaleros y trabajadores domésticos en Seattle, Washington. Aunque su situación es precaria e incierta, hay una mejoría frente a la transitoriedad e impermanencia de la vida en la frontera. Los migrantes en Seattle quieren contribuir a la sociedad en la que viven. En 2010, en el estado de Washington, los migrantes indocumentados fueron el 3,4\% de la población del estado y aproximadamente un $5,1 \%$ de su fuerza laboral (Passel y Cohn, 2011). Su trabajo no es insignificante: contribuyen a la actividad económica estatal con aproximadamente $\$ 6,4$ mil millones de dólares en producto estatal bruto (Perryman Group, 2008) y \$292,1 millones de dólares en impuestos estatales y locales (ITEP, 2013). Incluir en nuestra investigación a los jornaleros y trabajadores domésticos asociados a Casa Latina, nos permitió explorar las experiencias 
de migración y las nociones de hogar de los migrantes latinos (indocumentados) en Seattle, el centro urbano más grande del estado de Washington.

\section{Resultados en la frontera: "pequeños mundos" para una vida de transitoriedad extrema}

Mientras circulan en la zona de frontera entre EE.UU. y México, los migrantes se encuentran en uno de los momentos más vulnerables de su viaje migratorio. Ya no están en su lugar de origen (etapa pre-migratoria), y no han llegado todavía a su destino, donde se enfrentarán a los desafíos propios de la etapa inmediata, intermedia o de integración (Caidi et al., 2010). En la frontera, los migrantes están en un cruce de caminos entre el aquí y el allá, con sus pertenencias en un morral o en una bolsa plástica, y sus sueños y esperanzas a flor de piel. En este espacio fronterizo, los migrantes prefieren la información del voz a voz, sobre cualquier otra fuente, para compensar por la vulnerabilidad extrema de su experiencia impermanente en la frontera. Las referencias de voz a voz llegan de familiares y amigos, de otros migrantes y de proveedores de servicios humanitarios; son el modo preferido para identificar guías confiables que les ayuden a cruzar la frontera. Las amistades son profundas, toda vez que comparten miedos y expectativas. Aún así, son transitorias y se disolverán apenas una de las partes siga su camino. Como veremos, las prácticas de información de los migrantes en la frontera nos recuerdan la vida en la ronda (life in the round) y otros comportamientos propios del pequeño mundo y la pobreza de información (Chatman, 1999), pero estos comportamientos están limitados en el tiempo y el espacio por la transitoriedad y la vulnerabilidad del paso temporal de los migrantes por la frontera.

Conocimos a Lupe el primer día después de haber sido deportada. Llegó al albergue en shock después de pasar un tiempo en un centro de detención en Arizona y haber sido dejada en la frontera temprano esa mañana. Con lágrimas en los ojos, nos contó parte de su historia²:

Lupe: Salí de México cuando tenía 16 años. En los Estados conocí a mi marido, tuve a mis hijos, y viví por casi 12 años. Cuando estaba embarazada de mi último hijo, me agarró la migra. A mi esposo lo habían deportado así que los dejé deportarme a mí también, pensando que en México estaríamos bien. Viví allí por cuatro años pero no estábamos bien. Mi esposo cruzó de vuelta primero, después mandé a mis hijos, y luego traté de cruzar yo también pero no pude. Me agarraron. Me tuvieron por tres meses detenida. Me soltaron apenas esta mañana.

2. Todas las entrevistas han sido editadas para garantizar su brevedad y claridad. 
La experiencia de Lupe no es única. El informe de Pew señala que en la última década, el número de deportaciones de migrantes indocumentados en EE.UU. ha ido en aumento, llegando a ser casi medio millón solo en 2013 (González-Barrera y Krogstad, 2014). Miles de familias están en las mismas condiciones que Lupe: padres que no tienen una forma legal de reunirse con sus hijos, que nacieron en EE.UU. y sí son ciudadanos estadounidenses. Las acciones ejecutivas del presidente Obama, que ofrecen la posibilidad de no ser deportados a los migrantes que clasifiquen en ellas (principalmente aquellos con hijos nacidos en EE.UU. y sin pasado judicial), están varadas en los estrados judiciales, y Trump, el nuevo presidente electo, amenaza con suspender estas acciones ejecutivas y deportar a millones de migrantes indocumentados.

A la frontera muchos llegan de México y Centroamérica e intentan cruzar por primera vez; otros lo han hecho antes. La frontera es un punto de transición, de transitoriedad, un lugar temporal donde son vulnerables. Compartir la vulnerabilidad les permite crear vínculos profundos durante su corta estadía en la frontera. Están todos en la misma situación y la mayoría tiene la misma meta: llegar (o regresar) a EE.UU. Sus amistades son al mismo tiempo profundas y cortas. Chavalo, por ejemplo, nos muestra una imagen de sus nuevos amigos, todos tratando de escapar la violencia en Honduras (sus rostros fueron sometidos a un proceso de edición digital para asegurar su anonimato y proteger sus identidades).

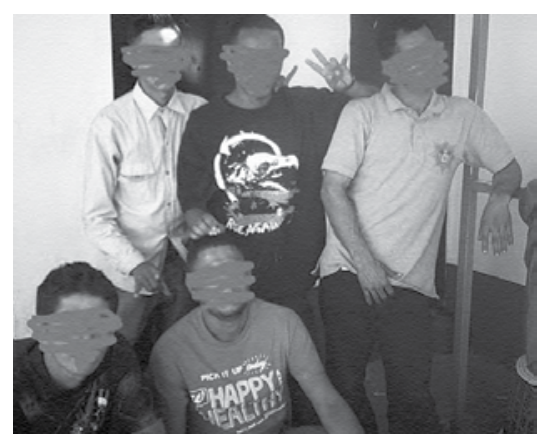

Chavalo: Bueno, todos somos hondureños, nos conocimos en el camino y nos hicimos amigos porque somos del mismo sitio. ¿Quién iba a pensar que nos encontraríamos tantas personas de Honduras? Cuando te vas, vas pensando que vas para el Norte, pero no sabes con quién te vas a encontrar en el camino, y te encuentras con todas estas personas de Guatemala, de Honduras, de México ...

\section{Información "de boca en boca" en el "pequeño mundo" de la frontera}

En la frontera los migrantes tienen un conjunto específico de necesidades de información: necesitan encontrar comida y refugio día a día; quieren que sus familiares y amigos sepan que están bien, y quieren encontrar la manera de cruzar a EE.UU. En este 
contexto, encontramos que la fuente de información más importante para los migrantes que se preparan para cruzar la frontera es el voz a voz.

Ricardo: ¿Cómo encontraste la información que te hacia falta para prepararte para cruzar?

Lupe: Es todo a través de los amigos. Preguntas por aquí y por allá quién conoce a alguien. $Y$ luego encuentras a alguien que conoce a alguien más, y te dan un número de teléfono y hablas con alguien. Es así cómo se hace.

R: Entonces ¿no usas las tecnologías, como la radio, la internet, la televisión?

L: No, nada, es solo de boca en boca y hacer una llamada.

R: Y de la tecnología usada por las patrullas fronterizas, ¿qué crees de eso?

L: Bueno, yo no crucé por las montañas. Pero lo que me dijeron mis amigos es que usan "moscos", creo que son los drones, algo que vuela y observa desde el alto. Y es así que te pillan. Y cameras, usan cameras. Y creo que también tienen filos, sensores, que si los pisas, saben que estás allí. Esto es lo que escucho de los demás. Pero ellos hacen tantas cosas que no sé. Esta es la segunda vez que cruzo, así que no sé mucho, la verdad. No tengo mucha experiencia.

Para los migrantes en la frontera la comunicación juega un papel crítico y, paradójicamente, las tecnologías de información exacerban su vulnerabilidad, ya que son usadas en su contra por las autoridades, los traficantes de drogas, los delincuentes y los que se dedican a la trata de personas. Incluso los teléfonos celulares pueden ser una fuente de peligro, ya que dar a conocer el número de teléfono de parientes o amigos puede llevar a que sean extorsionados por delincuentes (Newell et al., 2016). A los migrantes se les advierte que no anoten ningún número telefónico, que se rehúsen a usar celulares de desconocidos para hacer llamadas, y que borren el último número marcado cuando usen teléfonos públicos. Todo esto busca protegerlos a ellos y a sus parientes. A su vez, los parientes tienden a no contestar llamadas entrantes de números que no reconocen, lo cual dificulta aún más la comunicación con los que están en la frontera.

Los migrantes en la frontera están claramente en el extremo de la impermanencia del Continuo de la Transitoriedad (Vannini et al., 2016); sus prácticas de información tienen que ver con la cuidadosa búsqueda y uso de información que proviene de fuentes confiables que les permita navegar el momento efímero e impermanente de su viaje migratorio. En este contexto, encontramos algunas indicaciones de que Facebook podría llegar a ser una herramienta útil de comunicación, especialmente si se toma en cuenta que los cibercafés, bibliotecas y albergues humanitarios están empezando a ofrecer acceso público a los computadores y al internet, y que los migrantes tienen una creciente capacidad para usar Facebook y otras tecnologías digitales que les permiten mantener protegida la privacidad de sus contactos (al menos de los delincuentes) y les 
ayuda a narrar su viaje con textos e imágenes. Reportajes recientes han demostrado cómo Facebook ha sido usado por migrantes y refugiados del Medio Oriente en su viaje hacia Europa (Cunningham, 2015; Ensor, 2015), mientras que Noruega usa Facebook para publicar advertencias que buscan alejar a los migrantes (Bronsam, sin fecha) y Mark Zuckerberg quiere ofrecer Facebook gratis para todos los migrantes en los campos de refugiados en Europa (Blakeley, 2015). El uso de Facebook puede estar creciendo en la frontera entre México y EE.UU., así no haya mucha cobertura mediática sobre el tema (Reuters, 2014).

El énfasis en el voz a voz en el comportamiento de información de los migrantes en la frontera es consistente con la función de identidad de las tecnologías de información (TI) de la expresión de sí mismo (Carter y Grover, 2015). Bajo esta función, la tecnología es un medio que permite satisfacer las necesidades de información y es una herramienta para la expresión personal que no altera la noción de sí mismo. En la frontera encontramos ejemplos de migrantes que usan las TI para expresarse, documentando su viaje en palabras e imágenes. Ellos se expresan con canales en línea que ilustran sus situaciones y en los que se presentan a sí mismos como migrantes. Esto no solo demuestra cómo las TI pueden ser un medio para dar luz a la identidad personal de cada quien, sino que también explica las motivaciones por las cuales una persona decide usar las tecnologías de cierta manera. Las circunstancias riesgosas que experimentan y los pocos canales de comunicación a los que tienen acceso, pueden motivarlos a expresar la precariedad de su situación a través de las TI.

Chapin, nuestro entrevistado más joven, tiene apenas 18 años, y cuando trajo sus fotos para la entrevista de Fotohistorias, ya las había copiado a Facebook en un cibercafé cercano. Otros migrantes nos preguntaron si podíamos compartirles las fotos vía Facebook (estábamos ofreciendo imprimírselas en papel fotográfico).

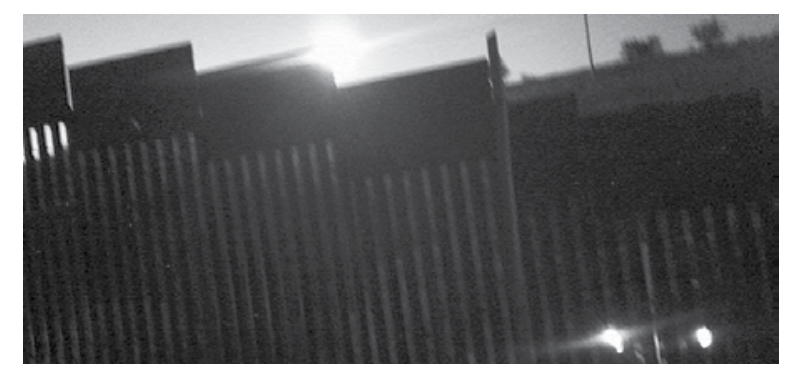

Chapin: Yo vengo de Guatemalay voy para Nueva York. Todo lo que estoy viviendo ahora es como una aventura. No estoy muy preocupado por nada. Estoy en esto como un aventurero. Estoy experimentando con diferentes países, yendo a diferentes estados de México, y viendo diferentes lugares. No lo veo como una cosa para tener miedo, sino como una aventura. Dejé mi país hace casi un mes. Y mira, estoy bien, nadie me ha robado, no me han hecho daño, y estoy aqui en la frontera ahora. $Y$ aqui tomé unas fotos del muro de la inmigración, que son las fotos que le mandé por Facebook a mi 
familia para que puedan ver exactamente dónde estoy. Para que puedan ver el muro, porque han oído hablar del muro y ahora aquí lo pueden ver en fotos. Por eso es que tomé estas fotos.

La información de boca en boca es crítica para encontrar un guía confiable, ya que no confiarían en alguien que publicita sus servicios en Facebook o a quien encontraron en una búsqueda en Google. Encontrar un guía confiable es probablemente la transacción más crítica de un migrante en la frontera. Chavalo insiste:

Chavalo: Lo que es más difícil es encontrar con quién ir, quién es un guía confiable. Cualquiera puede decir 'Sí, yo te llevo,' pero después te dejan tirado en el camino o te entregan a la migra.

Al igual que Chavalo, Chiapas nos trae una foto de sus amigos, y nos da una interpretación de sus emociones:

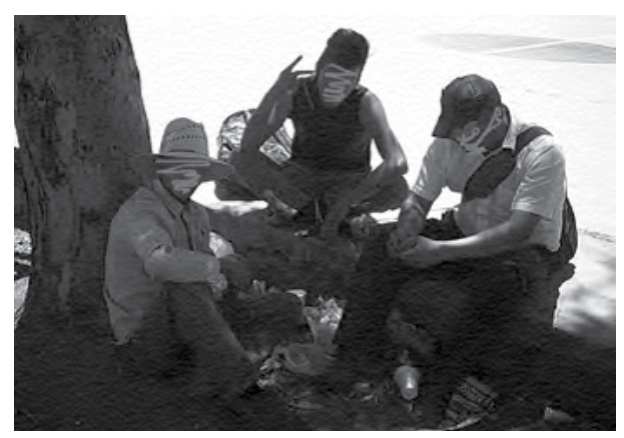

Chiapas: Parece que están felices, pero yo séque por dentro están preocupados. Por dentro están pensando: ¿Cómo voy a cruzar? ¿Lo voy a lograr? Por eso tomé esta foto: parece que están felices pero yo sé que por dentro cada uno de nosotros está preocupado.

Cada uno está preocupado, así en las fotos parezca feliz. Chiapas sabe que su amistad es pasajera. Una vez crucen la frontera, puede que nunca se vuelvan a ver.

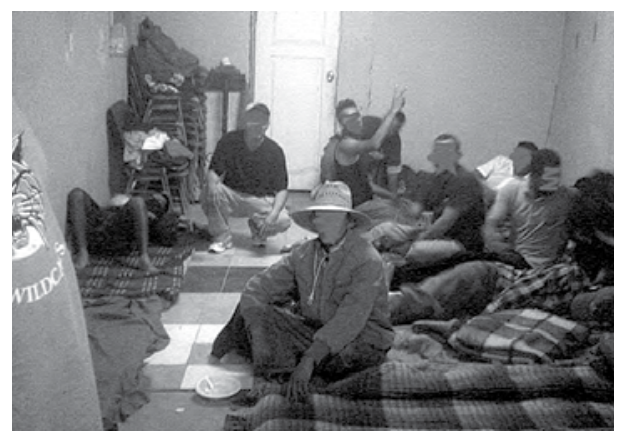

Chiapas: Siyo veo esta foto otra vez en unos cinco años podría decir: “'Dónde está esta persona? ¿Logró llegar a los Estados? ¿O estará de vuelta en su país? Estamos juntos aquí hoy, pero tan 
pronto como nos apartemos, cada uno en sus diferentes caminos, ya no nos volvemos a ver. Tal vez logran cruzar, pero nunca estaremos juntos otra vez. Por eso tomé esta foto con todos, aquí estamos todos juntos como estamos aqui hoy.

Los migrantes en la frontera están en la misma situación, compartiendo las mismas vulnerabilidades y la dificultad de encontrar fuentes confiables de información. Puede que terminen exhibiendo los comportamientos de información característicos de la "pobreza de información" de las comunidades marginadas estudiadas por Elfreda Chatman (Chatman, 1996; Chatman y Pendleton, 1995), particularmente sus estudios de mujeres en prisión (Chatman, 1999). Para Chatman, los miembros de la comunidad carcelaria se convierten en un grupo diferenciado, "los de adentro" (insiders), poco preocupados por lo que ocurra "afuera". Esto tiene como consecuencia una conceptualización de pequeño mundo que está desinformada dada la pobreza de información. A diferencia de los prisioneros o personal de las cárceles de los estudios de Chatman, los migrantes en la frontera están en un estado temporal de cambio constante. A pesar de esta diferencia, los migrantes están cohesionados tal y como "los de adentro" por una pared invisible de temor, vulnerabilidad e incertidumbre. Su pobreza de información pone su vida en riesgo y deben estar dispuestos a sacrificarlo todo para cruzar. Aún así, su pobreza de información como miembro de "los de adentro" es temporal ya que pronto estarán en otro sitio, ya no en la frontera, y los amigos de hoy serán solo un recuerdo de los momentos difíciles vividos durante su recorrido migratorio. Como Chiapas señaló, "no nos volveremos a ver". La pobreza de información es el resultado de la falta de acceso a los recursos de información necesarios, situación que se exacerba por su vulnerabilidad en un contexto desconocido y peligroso. No necesariamente saben cómo navegar el ambiente de información, y necesitan poder hacerlo para dar el salto y moverse hacia su destino.

Para finalizar esta sección en la frontera, regresemos a la historia de Lupe. El día después de haber sido deportada, tomó prestada nuestra cámara para tomar unas fotos, sin saber muy bien qué haría con ella. Su miedo y su rabia estaban intensamente presentes. Cuando la vimos de nuevo un par de días más tarde, estaba más tranquila y hablamos sobre las fotos que había tomado, las cuales incluían algunas de sus nuevos amigos en el albergue. 


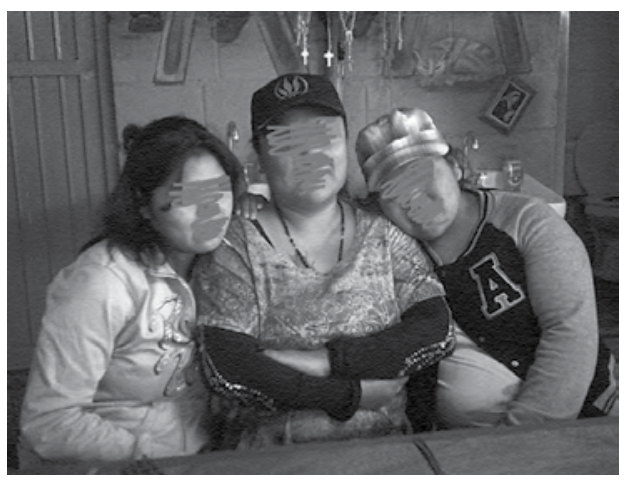

Tal y como otros migrantes en el albergue, Lupe encuentra alivio en las amistades pasajeras con otros que están en su misma situación, atrapados en un lugar crítico del engranaje de la vida en la frontera, viviendo en la transición entre "aquí" y "allá". Para Lupe, esta experiencia liminal de estar en medio de dos mundos (in-betweenness) es particularmente dolorosa porque sus hijos están en EE.UU. y ella no puede estar con ellos.

Éstas son mis amigas. Como somos todas mejicanas nos apoyamos mutuamente, aun cuando no nos conocemos bien. Estamos en el mismo barco, tenemos los mismos objetivos. Esta yo sé que también tiene a sus hijos en los Estadosy está tratando de cruzar por ellos. Somos mujeresy somos madres y somos mejicanas, y eso nos une. Yo estaba feliz de tomar una foto de ellasy verlas sonreír, después de todas las cosas terribles que hemos vivido.

Ricardo: ¿Y qué vas a hacer ahora?

Lupe: No sé. Si me quedo aquí, pues sería mejor, pero sería darle la espalda a mis hijos. Yo no puedo hacer eso, porque ellos son mi vida. Pero si trato de volvery me agarran y me tienen detenida por un año, pues tampoco quiero eso porque entonces no podría estar con mis hijos tampoco. Así que no sé. No séqué es lo que voy a hacer.

Cuando nos vimos con Lupe por última vez, tenía más confianza en sí misma, menos ansiedad y menos rabia. Le preguntamos cómo le había parecido participar en nuestro estudio:

Me gustó no pensar, sino sólo concentrarme en lo que está pasando en este momento de mi vida: que ya no estoy detenida, no estoy tan furiosa como estaba antes, en el CCA. Eso me cambió. Así que he estado pensando sobre todo eso. Ahora estoy libre, y puedo valorar otras cosas que antes no me parecían importantes. Les veo sus sonrisasy pienso, sí, todos tenemos problemas, pero también tenemos que seguir adelante. Cuando vi esa montaña, esa colinita con las casas, sentí pazy tranquilidad, la paz interior que uno necesita. Estas fotos son también memorias. Me dan memorias. No sési estaréotra vez en este pueblo fronterizo, pero ahora tengo las memorias de haber estado aquí. 
Cuando lo preguntamos, una vez más, si sabía qué iba a hacer ahora, nos anunció con una sonrisa: "Ahora sí sé lo que voy a hacer ahora”. No preguntamos más.

\section{Resultados en el lugar de destino: comportamientos híbridos entre "aquí" y "allá"}

En la experiencia de la migración, el punto de llegada es a veces parte del viaje, (o, como en la experiencia de Odiseo, el destino ES el viaje mismo). Hemos visto cómo los migrantes viven la transitoriedad y la vulnerabilidad en su vida entre "aquí" y "allá” y cómo algunos de sus comportamientos de información se parecen a los comportamientos de información en contextos de pobreza de información propios de los "pequeños mundos" de Chatman (Chatman, 1999). Sin embargo, la pobreza de información vivida por los migrantes en la frontera es apenas temporal, así cómo sus amistades son temporales y fugaces, parte de la transición que todos están atravesando en el punto de quiebre de la vida en la frontera. El destino no siempre resulta ser el que hubiesen preferido, y no es siempre estático. Las fases progresivas definidas por Caidi y sus colegas establecen etapas (a veces sobrepuestas) de asentamiento que son especialmente problemáticas por la linealidad y continuidad que asumen entre la etapa inmediata (al llegar), la intermedia (al obtener acceso a servicios locales) y la etapa de integración (al adaptarse e integrarse). La experiencia de los migrantes rara vez encaja en estas etapas progresivas, y la de los migrantes indocumentados quizás encaja aún menos, dada la transitoriedad que se extiende y que llega como consecuencia de la exclusión política, social y económica y el temor constante de ser detenidos o deportados. En esta sección nos enfocaremos en las vivencias de los migrantes (indocumentados) en su punto de llegada, tal y como nos la narraron participantes de Fotohistorias en Seattle, Washington.

\section{La superación del "pequeño mundo": cuando tienes un lugar al cual llamar hogar}

Gilda, una migrante que en el pasado fue indocumentada y ahora hace parte del equipo de Casa Latina, puede ser la personificación de las metas y aspiraciones de muchos de los jornaleros y trabajadores domésticos (indocumentados) en Seattle. Gilda tiene una sonrisa generosa y ojos brillantes y luminosos. Con una voz pausada nos cuenta sobre su viaje migratorio y su trabajo al servicio de otros migrantes en Seattle y alrededor de EE.UU. Es una persona que trabaja por los derechos de los migrantes y nos comparte varias imágenes de marchas, protestas y demostraciones. 


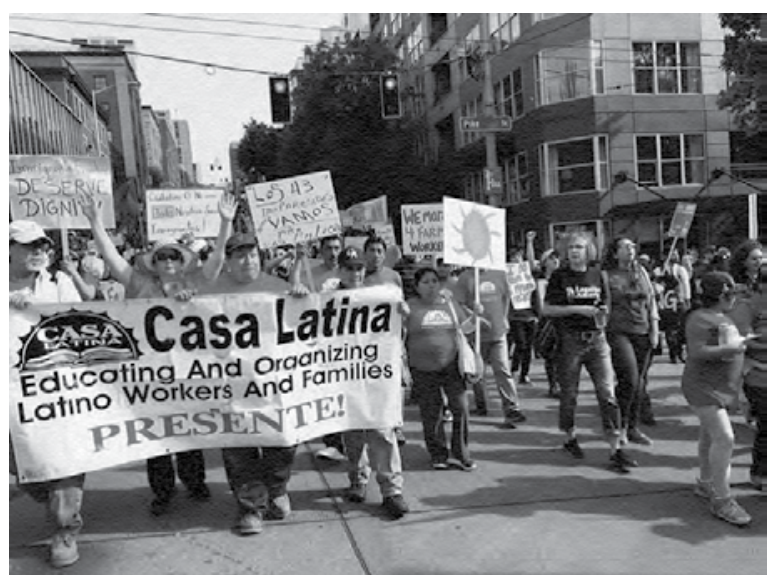

Gilda: En mi trabajo, yo abogo por los derechos de los inmigrantes en este país. Viajo por todo el país para hacer manifestaciones, marchas y llevar la voz de las personas con las que yo trabajo. Además, yo soy parte de esa misma situación. Estoy en una circunstancia similar que no es diferente de la de otras personas. ¿Por qué lo hago de esta manera? Lo hago porque tengo fuerza para seguir luchando por mi misma y por mis propios derechos. No es lo mismo estar en el otro lado cuando luchas por los inmigrantes, si te encuentras en la misma situación. Por esta razón precisa, se lucha con más fuerza.

Gilda es inmigrante, y trabaja por la defensa de los derechos de otros inmigrantes. Al igual que Armando y Mariana, todos empezaron siendo beneficiarios de los servicios proveídos por la organización en la que ahora trabajan. También es uno de los pocos casos de una migrante indocumentada que logra legalizar su estatus e "integrarse" mejor. Al poco tiempo de haber completado nuestro trabajo de campo en Seattle, Gilda nos contó emocionada que finalmente había recibido su residencia legal. Al momento de la entrevista, aún estaba esperándola, y el resultado del proceso, que ya llevaba años en curso, todavía era incierto.

Gilda: Hace como 15 años entré al país con una visa de turista. Ahora me puedo quedar porque tengo permiso de trabajo. Alguien me estaba ayudando con los documentos para mi residencia pero resultó siendo un fraude, y estoy otra vez comenzando a hacer mis papeles. No me puedo ir del país, porque no podría volver a entrar. No hay un solo día que pase en el que no piense en obtener mi residencia permanente. Esta imagen muestra lo que siento por el servicio de la inmigración y ciudadanía. Siento que es un servicio muy injusto. Es un servicio que juega con la vida y los sentimientos de seres humanos... la política. La inmigración es una política. No es la gente. Es sólo la politica quejuega con los sentimientos de los seres humanos. Te lastiman como si fueras un enemigo. Me indigna saber que hay un servicio que supone trabajar con las leyesy ser para la gente. No está respondiendo de esa manera debido a razones burocráticas. Este tema me indigna muchísimo. 


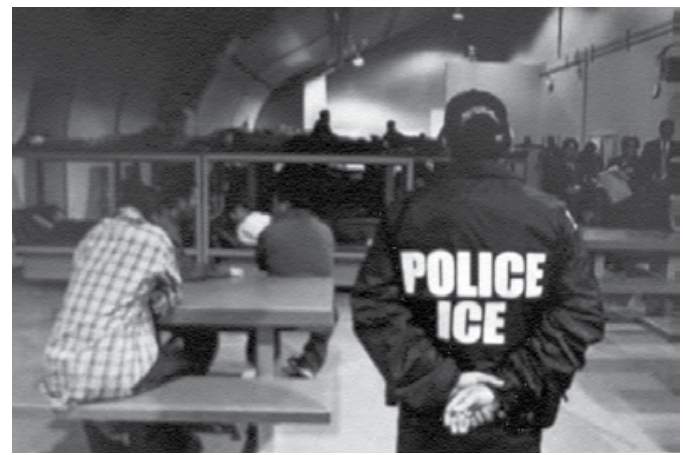

Foto de una foto de la policía migratoria, tomada por Gilda. Reproducida aquí con autorización de Getty Images.

La indignación de Gilda se ha convertido, por medio de su trabajo por la incidencia en las políticas públicas, en acción. En Casa Latina, es una educadora querida, y está lejos del "pequeño mundo" pobre de información de los migrantes en la frontera. A diferencia de ellos, es la mediadora de la información, alguien que trasciende las fronteras tendiendo puentes en apoyo a los migrantes en Casa Latina y en EE.UU. Sus prácticas de información incluyen la búsqueda de una voz política y de una participación fortalecida en la arena pública, siendo ambos rasgos característicos de la etapa de integración de la migración (Caidi et al., 2010).

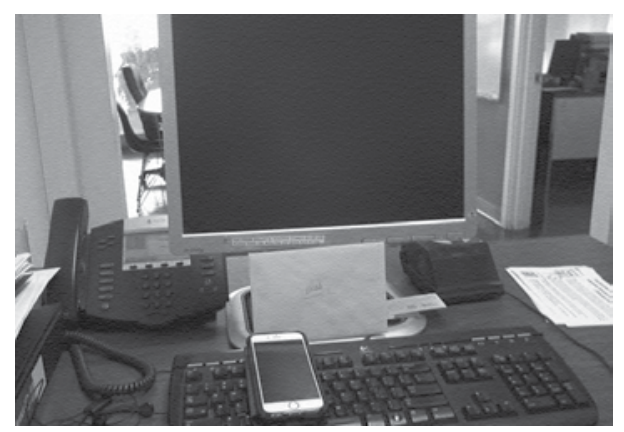

Gilda: Éste es mi portátil, mi celular, y mi teléfono. Aqui es donde trabajo, donde crezco cada día, donde descubro mi lado profesional. Estas herramientas me empujan hacia el éxito. Esto significa mucho para mí. Aprendo cómo argumentar y cómo luchar. También aprendo cómo encontrar reconciliación. Trabajo con personas de diferentes culturas y niveles educativos. Entiendo que no es sólo que las personas tengan un problema y hay que confrontarlos, sino que también hay que tratar de entender la raiz del problema. Estas herramientas me han enseñado muchas cosas en mi trabajo. Yo estoy abierta a aprender porque soy un ser humano. 
La descripción de Gilda de su computador, celular y teléfono fijo y cómo los percibe como herramientas que la acercan al éxito, puede estar relacionada con la función de identidad de las TI en la expansión de sí mismo (Carter y Grover, 2015). Gilda trabaja atendiendo a migrantes en una situación que conoce bien, pues es una situación que alguna vez fue suya. El trabajo no es lo único que se ha estabilizado en la vida de Gilda. También está orgullosa de mostrarnos una imagen de su casa, un lugar que es propio.

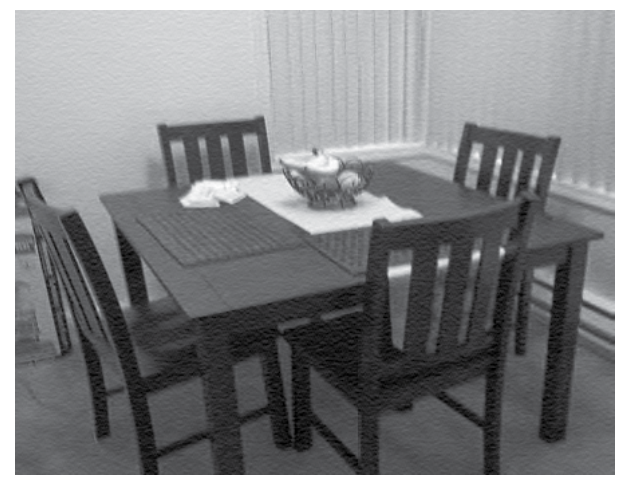

Gilda: Este es mi hogar. Hay una mesa con cuatro asientos. iSi sólo pudiera decirte cuántas cosas han sucedido en esta mesa! Comemos, junto con mi hermana y sus hijos y su esposo. También me siento allí con mi novio y con amigos que vienen a visitarme. Para mi este lugar es muy sagrado. Es mi lugar favorito en el mundo. Mi propio espacio. Aquí tengo la sensación de que yo soy.

Un lugar propio, un lugar donde puede sentir que ella ES. Esa es la meta y la aspiración última de los migrantes que buscan establecerse en su lugar de destino. Se convierten en proveedores de información para otros, y empiezan a construir una cotidianidad más duradera, ya no transitoria (Vannini et al., 2016). Pero la experiencia de Gilda es, en muchos sentidos, excepcional. La mayoría de los migrantes (indocumentados) que participaron en nuestro estudio, viven vidas mucho más precarias, tratando de pagar sus cuentas con sus ingresos de jornaleros o trabajadores domésticos. Las condiciones precarias del empleo y de la cotidianidad están diametralmente opuestas con las conquistas de Gilda, y ellos no se encuentran tan cómodamente "integrados", ni viven de manera más "duradera" (no transitoria). Los migrantes (indocumentados) tienden a vivir y a tener experiencias que se ubican en el espacio entre lo "moderadamente transitorio" y lo "moderadamente duradero", donde tienen que equilibrar sus prácticas de información entre la cuidadosa búsqueda de información de fuentes confiables y la socialización generosa de información con otros miembros de su comunidad.

Como los migrantes en el albergue en la frontera, los migrantes en Seattle a menudo encuentran su comida diaria en centros de distribución gratuita de comida y en otros albergues, ambos lugares de paso para los excluidos y marginados. Varios de nuestros 
participantes reportaron estar o haber estado sin hogar en algún momento, durmiendo en albergues e incluso en las calles. Ventura, por ejemplo, parece haber pasado largos períodos en albergues para las personas que no tienen casa.

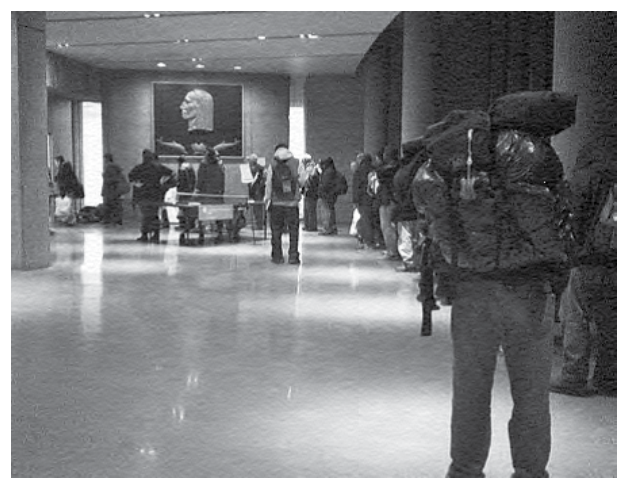

Ventura: Yo vivo en un albergue en la alcaldía, con otras personas que tampoco tienen dónde dormir. Desde que llegué a Seattle me he quedado alli, sobre un colchón. Mi casa, mi hogar, es donde caiga. Como dice el dicho, donde cae la noche, también cae el cuerpo.

La transitoriedad y la impermanencia son parte de la vida cotidiana de muchos de los migrantes (indocumentados) en Seattle, tal y como lo expresan en las fotos e historias alrededor del hecho de no tener casa. El temor a ser deportados es una constante, pero la vida sigue y muchos establecen rutinas que empiezan a parecerse a las vidas "ordinarias" descritas por Armando y Mariana en la frontera, o Gilda en Seattle. Muchas de las rutinas cotidianas representan comportamientos de información que van más allá de los "pequeños mundos" propios de los contextos donde hay pobreza de información, tal y como describimos que ocurría para los migrantes en la frontera. Construyendo sobre un trabajo previo con migrantes en Casa Latina, los mundos de información de los migrantes que ahí se encuentran involucran computadores, celulares, transporte y el inglés (Barón et al., 2013).

\section{Los teléfonos celulares y computadores amplían los mundos de información de los migrantes}

Casi todos los miembros de Casa Latina son dueños de celulares, y muchos de ellos tienen algún grado de familiaridad con el uso de los computadores, en parte gracias a clases de cómputo que se ofrecen desde el 2011, cuando una sala de cómputo fue creada 
con el apoyo financiero de la Alcaldía de Seattle y profesores voluntarios. Los teléfonos celulares sin conexión a internet han sido lentamente reemplazados por los teléfonos inteligentes, smart phones, pero a un costo que va mucho más allá del valor de compra, tal y como lo describe Servando, uno de los primeros miembros de Casa Latina que participó en nuestro proyecto de fotografía participativa:

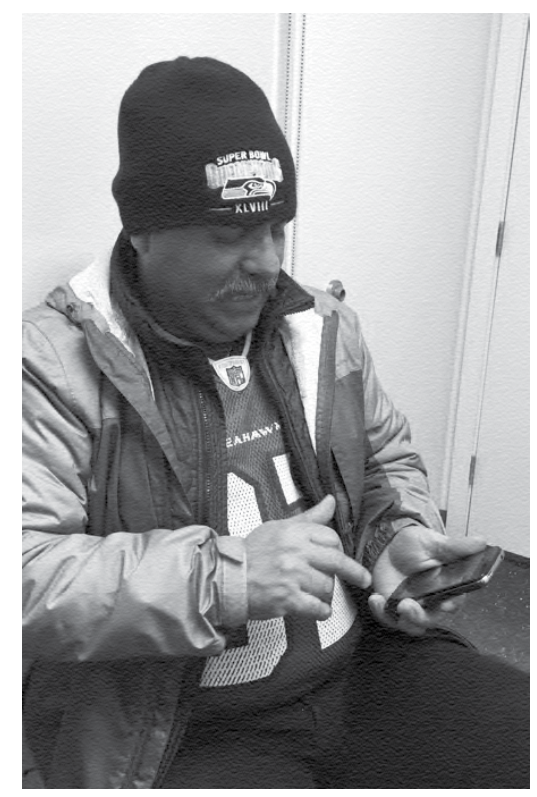

Servando mostrando cómo tuvo que aprender a aprender el teléfono (foto: R. Gomez)

Servando: Cuando primero compré un smart phone no sabía cómo usarlo y perdí un trabajo porque no supe cómo contestar la llamada. Me llamaban y yo sólo tocaba la pantalla así, y no contestaba. Fue sólo mástarde que alguien me dijo que hay que arrastrarlo hacia el lado con el dedo para contestar el teléfono. Ahora ya sé cómo contestar. Es fácil. Todo es fácil cuando uno ya sabe.

Los teléfonos son una necesidad vital para los trabajos en las precarias condiciones de empleo de los jornaleros. Deben poder recibir llamadas y mensajes de texto de potenciales empleadores. Pero para los migrantes, también son una herramienta para comunicarse con la familia, especialmente cuanto están lejos. La combinación de teléfonos y computadores como método de comunicación fue mencionada por varios de nuestros participantes. Juan, por ejemplo, sólo cuenta con el teléfono para comunicarse: 


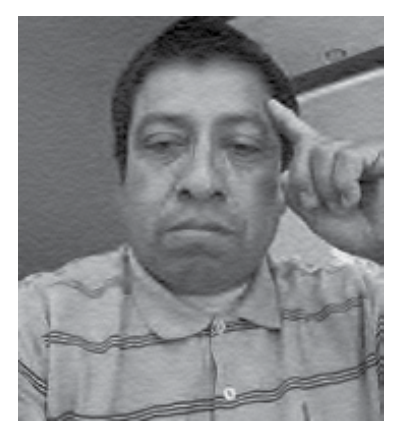

Juan: Yo llamo a mi mamá. No le digo las cosas malas que me han pasado, sólo le digo las buenas. Compro tarjetas prepagadas en la tienda Azteca en Jackson, y las uso para hacer llamadas de larga distancia. La llamo unas 405 veces por semana. En realidad, no sé cómo usar una computadora o un celular, solo sé hablar y me gusta escuchar la voz y hablar con mi familia. Me hace mucha falta mi familia. El celular que tengo no es muy sofisticado. Puede tomar fotos, pero no las puedo mandar a mifamilia en Guatemala. Se lasmando a un sobrino en Nueva York, yél se las hacellegar.

Ventura no sabía cómo usar la cámara que le prestábamos para el proyecto, pero estaba feliz de pensar que iba a poder agregar sus fotos a su cuenta de Facebook. Como los migrantes en la frontera, algún día puede que esté en otro sitio, y Facebook le ayuda a guardar los recuerdos de su tiempo en Seattle. La tecnología en general y Facebook en particular, no son solo herramientas que ayudan a comunicarse, sino también herramientas que mantienen los recuerdos. La memoria histórica es importante, no sólo para los migrantes en la frontera o en su punto de destino. Como lo veremos más adelante, también es un componente importante en el mundo de información de los migrantes en su lugar de origen.

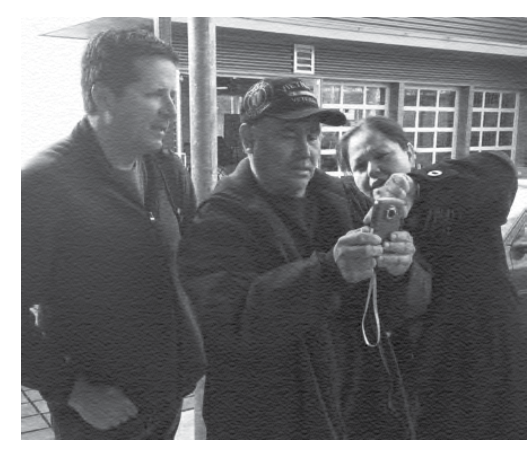

Foto de Ventura con miembros del equipo de investigación mostrándole cómo usar la cámara para Fotohistorias (foto: S. Vannini) 
Ventura: Ahi estoy yo con unos amigos: con ustedes, los entrevistadores, ustedes me están entrevistando. Aqui me están mostrando cómo usar la cámara. Me gustaría que me manden las fotos que tomé a mi Facebook. Yo tengo mis fotos en Facebook para guardarlas como recuerdos. Tal vez un día estaré en otro lugar, entonces no es sino abrir Facebooky veo los recuerdos.

Además de los teléfonos celulares, los computadores también son herramientas importantes para la expansión del mundo de información de los migrantes (indocumentados) en Seattle. Ramón, por ejemplo, es un apasionado inesperado de los computadores. A los 72 años, es el participante de Fotohistorias con más edad, y quizás el que mejor sentido del humor tiene. Aspira a ser escritor y fotógrafo, y se enorgullece de ser jardinero.

Ramón: Esta es una foto de un portátil. Yo tengo uno pero ya no sirve más. Ahora uso mi celular. Tengo dos celulares, uno es un teléfono básico que sí tiene línea telefónica, y el otro es un smart phone que no tiene línea. Le pongo un teclado de Bluetoothy lo uso como tablet. Miro programas en inglés, juego juegos, juegos de matemáticas, miro cosas en YouTube, escucho música. Así es como me relajo, porque si me quedo sólo mirando películas me da sueño.

\section{La biblioteca pública expande los mundos de información de los migrantes}

Además de su pasión por los computadores y la tecnología, que lleva incluso a sacrificar clases de inglés presenciales, los ojos de Ramón brillan cuando nos habla de su lugar favorito en la ciudad: la Biblioteca Pública de Seattle ${ }^{3}$.

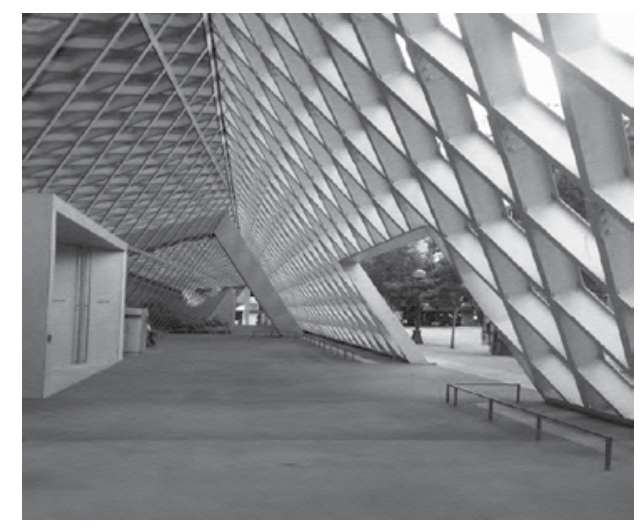

Ramón: En la biblioteca puedes mirar libros y si te gusta uno lo lees, y si no, lo dejas ahi y no lo tienes que comprar. Hay muchos temas que puedes explorar. A mi me gusta Pablo Neruda. Me 
gusta escuchar sus poemas. Yo voy a la biblioteca cada vez que puedo. Si no encuentro trabajo aqui en Casa Latina, puedo ir a pasar todo el día en la biblioteca y asi superarme. Puedo llenar todo el conocimiento que me hace falta, y es también un lugar seguro donde iry pasar el tiempo, aun si no tengo nada que hacer. Es muy cómodo alli porque afuera hace frío y estálloviendo y en la biblioteca no lluevey no hace frío, y no tienes que pagar nada. Aqui en Seattle es una estructura muy bella. A cualquier nivel que vayas, hay mucho qué ver y qué admirar.

En la biblioteca, Ramón encuentra, no sólo un lugar seguro donde pasar el tiempo (como un albergue), sino también un sitio donde puede ir a crecer como persona. Aunque el grado de pasión de Ramón por los computadores y por la biblioteca pública puede parecer extremo, no es el único. Otros migrantes en Seattle también nos trajeron fotos de la biblioteca como un lugar importante en sus vidas. Servando, por ejemplo, nos trajo esta foto de lo que llamó "la oficina":

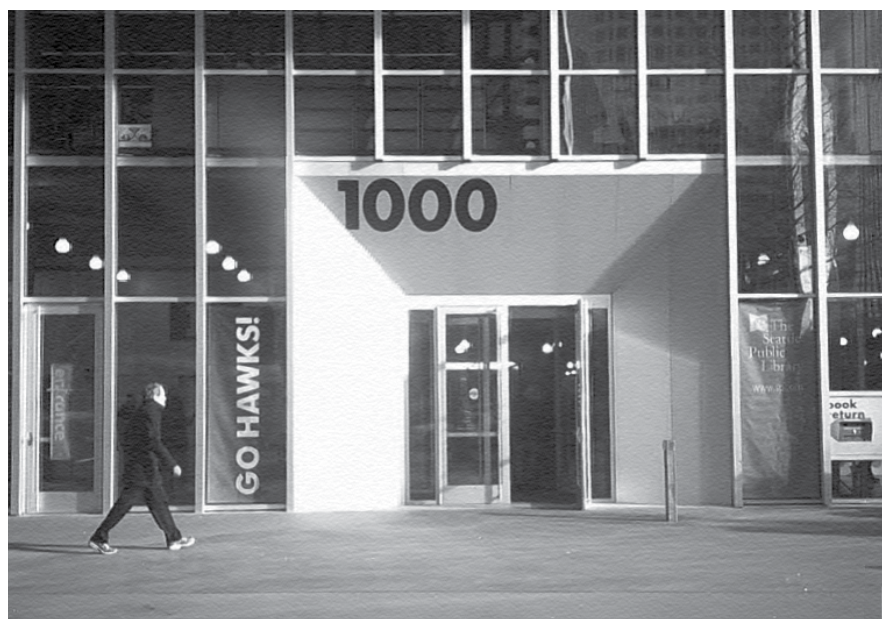

Servando: Esta es la biblioteca central, pero la llamo también "la oficina" porque para muchos es la oficina de toda mi gente. Aquí nos fuimos a ver los partidos de fútbol de los Seahawks. Esta es la entrada de la biblioteca... Siempre he querido ver las auroras, las auroras boreales, porque nunca las he visto. Me gustaría ir a la biblioteca para aprender sobre todas estas cosas. Yo leo los periódicos en la biblioteca. Para todo el mundo en la calle la biblioteca es un refugio. Igual que una iglesia, no te pueden echar de allí. En la biblioteca central la mayoría son personas sin hogar, y el otro $20 \%$ son personas normales que viven en sus propias casas o que trabajan allí.

Además de ser un lugar de aprendizaje, Servando ve la biblioteca como un refugio, un santuario. Para Ventura, la biblioteca es, no sólo el primer lugar al que fue cuando llegó a Seattle, sino también el lugar en el que aprendió a usar computadores. 


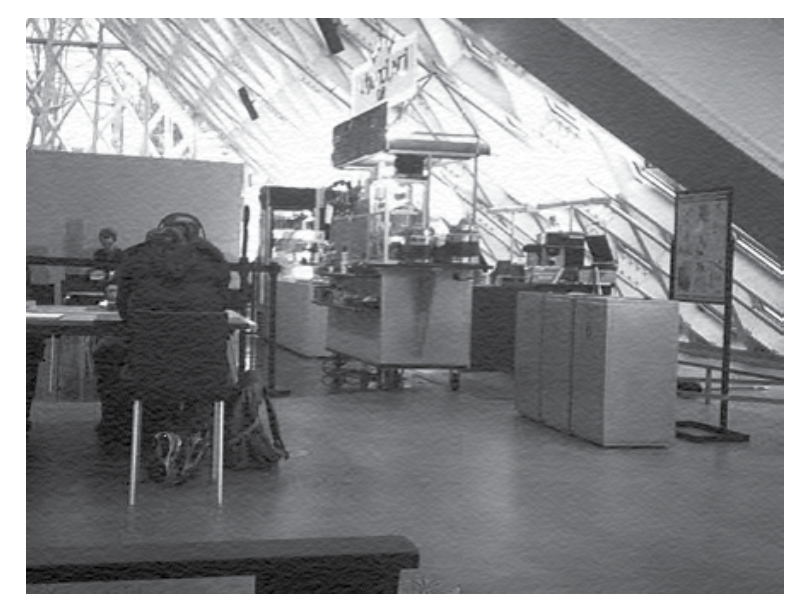

Ventura: Esa es la biblioteca. Esa misma la conocí como al tercer día de estar en Seattle. Un amigo me dijo: "Quieres hablar con tu familia? Yo te enseño cómo entrar a la computadora." Es por eso que acepté y así es como conocí la biblioteca. Él me rogó: "Vamos a la biblioteca!" Porque a mi no me gusta leer libros, pero un día acepté ir y hasta el día de hoy sigo yendo ahí. Yo uso la computadora para el traductor, y también veo películas, con subtitulos. Y a veces, hablo con mi familia. Yo siempre voy a la biblioteca a usar el traductor, porque soy muy aficionado al inglés. Aprendo muchas palabrasy frases alli. Veo videos también, pero tienen que estar subtitulados. Sino tienen los subtítulos no me gusta, no entiendo nada. Pero si aparecen los subtitulos y la persona está hablando en inglés entonces síme gusta. Así es que por eso voy a la biblioteca, esa es mi diversión.

La biblioteca pública es un lugar que contribuye a ampliar los mundos de información de los migrantes (indocumentados), dilata los límites del "pequeño mundo" pobre en información y ubica a los migrantes frente a un mundo más grande, más rico en información, en el cual pueden desarrollarse como personas, aprender, encontrar entretenimiento (con subtítulos) y comunicarse con parientes y amigos. La biblioteca pública es, para el migrante (indocumentado), un pasaporte a un mundo más grande de información, recursos y oportunidades. Les brinda la posibilidad de alejarse de estar cuidadosamente buscando información de fuentes confiables, rasgo característico de quien vive una existencia transitoria y efímera, hacia una búsqueda y uso de la información que es más ambiciosa y abierta y que proviene de fuentes más diversas. La transitoriedad moderada puede convertirse en permanencia moderada cuando se le agrega información y recursos de aprendizaje. El punto de quiebre pueden ser clases de inglés o de otras habilidades.

Las prácticas de información de los migrantes nos revelan una progresión clara entre el uso de un teléfono celular exclusivamente para hacer o recibir llamadas, y un número creciente de teléfonos inteligentes, tablets y computadores usados como herramientas 
para conseguir información, comunicarse o entretenerse. La biblioteca pública es una puerta de entrada a un universo de información más grande, el cual al verse complementado por clases de inglés y formación en otras habilidades, ayuda a consolidar las prácticas de información de los migrantes mientras se asientan y se integran; aunque rara vez se integran verdaderamente, dada la irremediable y generalizada exclusión a la que están sujetos por tener estatus como indocumentados. Aún así, sus prácticas de información les ayudan a alejarse de la impermanencia y a acercarse a la permanencia: de ser cuidadosos buscadores de información de voz a voz, a ser usuarios hábiles de información que proviene de fuentes diversas y finalmente a ser generosos proveedores de información para otros (Vannini et al., 2016). Oscilando entre lo moderadamente transitorio y lo moderadamente estable, los migrantes viven distintos aspectos de la etapa inmediata y la etapa intermedia de la migración, de una manera iterativa y cíclica que cuestiona la presunción lineal del continuo de la migración (Caidi et al., 2010). El Continuo de la Transitoriedad no se ha desarrollado del todo (Vannini et al., 2016), pero puede ser una herramienta conceptual más útil que el continuo de la migración (Caidi et al., 2010) para entender las prácticas de información de los migrantes indocumentados.

\section{Conclusiones}

Analizamos aquí las prácticas de información de migrantes latinos en los contextos de transitoriedad y vulnerabilidad de su paso por la frontera entre México y EE.UU. Estas prácticas muestran una progresión no-lineal entre la pobreza de información que se da en los "pequeños mundos" de la frontera, y la superación y ampliación de estos "pequeños mundos" a medida que la vulnerabilidad y la incertidumbre se van superando con el establecimiento paulatino en la nueva vida en el lugar de destino. Sin embargo, la vulnerabilidad no se acaba completamente, ni el sentido de transitoriedad, dado el riesgo permanente de ser deportados, y las condiciones de empleo precario como jornaleros que viven los migrantes participantes en este estudio.

La superación de la pobreza de información del pequeño mundo se facilita cuando los migrantes comienzan a tener un sentido de pertenencia más fuerte y comienzan a reasumir su voz y su participación en la vida de la comunidad, eventualmente llevando a su participación en marchas y protestas para defender sus derechos, los cuales les son negados en su condición de migrantes (indocumentados). En este tránsito juegan un papel las agencias de apoyo a los migrantes y las bibliotecas públicas, que ofrecen un espacio seguro para buscar información y ampliar la visión de mundo, y las tecnologías de información como los teléfonos celulares, smart phones, tablets y computadoras, las cuales amplían el espacio de información y abren nuevas oportunidades de identidad con el uso de la tecnología. 
Estas prácticas de información entre migrantes latinos en EE.UU. se diferencian (y complementan) de las prácticas de migrantes al interior del país en Colombia, que fueron estudiadas también en esta investigación y se presentan en un artículo aparte en el próximo número de esta revista. Entre los participantes en Colombia la experiencia de transitoriedad y vulnerabilidad es diferente, más bien centrada en la construcción de un territorio para la identidad y las generaciones futuras, un lugar de donde las personas no se tengan que ir para buscar un futuro mejor.

En todos estos casos constatamos que las prácticas de información en contextos de migración están relacionadas con el nivel de vulnerabilidad y transitoriedad de las experiencias de los migrantes, pero que las prácticas de información, igual que las experiencias de migración, son dinámicas y cambiantes, aunque no progresan en forma lineal. El continuo de la transitoriedad en las prácticas de información debería más bien ser una espiral cíclica e iterativa, un anillo de moebius en el que coexisten las prácticas de pobreza de información de los pequeños mundos con las prácticas más amplias de participación ciudadana en relación con un mundo más amplio, más o menos mediadas por la información de boca en boca, y apoyadas por tecnologías de información (celulares, smart phones, computadoras) y organizaciones de apoyo como las bibliotecas públicas y centros comunitarios. Las experiencias de los migrantes latinos (indocumentados) mantienen una dosis permanente de vulnerabilidad y transitoriedad a medida que aprenden a navegar la vida cotidiana en su nuevo lugar de destino, por lo que sus prácticas de información oscilan entre pobreza y riqueza de información, sin alcanzar la meta de echar raíces profundas en su nuevo territorio.

\section{Referencias}

AGAMBEN, G. (1998). Homo Sacer: Sovereign Power and Bare Life. Stanford, Calif: Stanford University Press.

BARON, L. F., Neils, M., \& Gomez, R. (2013). Crossing new borders: computers, mobile phones, transportation and English language among Hispanic day laborers in Seattle. Journal of the American Society for Information Science and Technology (JASIST), 64(5).

BLAKELEY, K. (2015, September 27). Mark Zuckerberg wants to bring Facebook to migrants. Daily Mail.

BRONSAM, G. (n.d.). Norway is using Facebook to send a stark message to migrants. BBC News. Retrieved from http://www.bbc.com/news/magazine-34813650

CAIDI, N., Allard, D., \& Quirke, L. (2010). Information practices of immigrants. Annual Review of Information Science and Technology, 44(1), 491-531. 
CARTER, M., \& Grover, V. (2015). Me, My Self, and I (T): Conceptualizing Information Technology Identity and its Implications. MIS Quarterly, 39(4).

CHATMAN, E. A. (1996). The Impoverished Life-World of Outsiders. Journal of the American Society for Information Science, 47, 193-206.

CHATMAN, E. A. (1999). A theory of life in the round. Journal of the Association for Information Science and Technology, 5o(3), 207.

CHATMAN, E. A., \& Pendleton, V. E. (1995). Knowledge gap, information-seeking and the poor. The Reference Librarian, 23(49-50), 135-145.

CHOMSKY, A. (2014). Undocumented: how immigration became illegal. Beacon Press.

COHA. (n.d.). Young Voices From the Border: Fear and Unaccompanied Migrant Children. Retrieved from http://www.coha.org/young-voices-from-the-border-fear-and-unaccompanied-migrantchildren/

CUNNINGHAM, E. (2015, September 16). Facebook is the new travel guide for Iraqis headed to Europe - The Washington Post. The Washington Post. Retrieved from http://wpo.st/YUAbo

ENSOR, J. (2015, September 20). The Facebook group helping migrants reach Europe. The Telegraph. Retrieved from http://www.telegraph.co.uk/news/worldnews/europe/croatia/11877508/The-Facebook-group-helping-migrants-reach-Europe.html

FISHER, K., Marcoux, E., Miller, L., Sanchez, A., \& Ramirez Cunningham, E. (2004). Information Behavior of Migrant Hispanic Farm Workers and their Families in the Pacific Northwest. Information Research, 10. Retrieved from http://informationr.net/ir/10-1/paper199.html

GOMEZ, R., \& Vannini, S. (2015). Fotohistorias: Participatory Photography and the Experience of Migration. Charleston, SC: CreateSpace.

GONZALEZ-BARRERA, A., \& Krogstad, J. M. (2014, October 2). U.S. deportations of immigrants reach record high in 2013. Retrieved June 8, 2015, from http://www.pewresearch.org/fact-

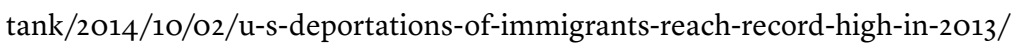

ITEP. (2013). Undocumented Immigrants' State and Local Tax Contributions. Washington DC, USA: Institute of Taxation and Economic Policy. Retrieved from http://www.itep.org/pdf/undocumentedtaxes.pdf

IZCARA PALACIOS, S. P. (2012). Violencia contra inmigrantes en Tamaulipas. European Review of Latin American and Caribbean Studies, 93, 3-24.

IZCARA PALACIOS, S. P. (2016). Los Transmigrantes Centroamericanos En México. Latin American Research Review, 5o(4), 49-68. https://doi.org/10.1353/lar.2015.0050

IZCARA PALACIOS, S. P. (2016). Violencia postestructural: migrantes centroamericanos y cárteles de la droga en México. Revista de Estudios Sociales, (56), 12-25. 
IZCARA PALACIOS, S. P., \& Andrade Rubio, K. L. (2015). Causas e impactos de la deportación de migrantes centroamericanos de Estados Unidos a México. Estudios Fronterizos, 16(31), 239-271.

JENSEN, B. (2002). Service to day laborers: a job libraries have left undone. RefUser Serv Q Reference \& User Services Quarterly, 41, 228-33.

NAIL, T. (2015). The Figure of the Migrant. Stanford, California: Stanford University Press.

NEWELL, B. C., \& Gomez, R. (2014). Informal Networks, Phones and Facebook: Information Seeking and Technology Use by Undocumented Migrants at the U.S.-Mexico Border. Proceedings of iConference 2015, Rochester, NY. Retrieved from http://papers.ssrn.com/abstract=2539396

NEWELL, B., Gomez, R., \& Guajardo, V. (2016). Information seeking, technology use, and vulnerability among migrants at the US-Mexico border. The Information Society. Retrieved from http://www.narcis.nl/publication/RecordID/oai:tilburguniversity.edu:publications\%2Fofa2fd3c-2b33-45eb-be12-69f248c53ceb

PASSEL, J. S., \& Cohn, D. (2011). Unauthorized Immigrant Population: National and State Trends, 2010 (Pew Research Center). Pew Hispanic Center. Retrieved from http://pewhispanic.org/files/reports/133.pdf\#page $=25$

PERRYMAN GROUP. (2008). An Analysis of the Economic Impact of Undocumented Workers on Business Activity in the US with Estimated Effects by State and by Industry. Waco, Texas, USA. Retrieved from http://www.ilw.com/articles/2008,1008-perryman.pdf

REUTERS. (2014, July 5). Migrantes y “polleros” utilizan Facebook para acordar el cruce de frontera. La Jornada. Mexico. Retrieved from http://www.jornada.unam.mx/ultimas/2014/o8/o5/migrantes-y-polleros-utilizan-redes-sociales-para-organizar-paso-por-la-frontera-7977.html

SAVOLAINEN, R. (2008). Everyday information practices: a social phenomenological perspective. Scarecrow Press.

SCHILLER, N. G., Basch, L., \& Blanc, C. S. (1995). From immigrant to transmigrant: Theorizing transnational migration. Anthropological Quarterly, 48-63.

VANNINI, S., Gomez, R., \& Guajardo, V. (2016). Security and Activism: Using participatory photography to elicit perceptions of Information and Authority among Hispanic migrants in the U.S. In Proceedings of iConference 2016. Philadelphia, PA.

YEFIMOVA, K., Neils, M., Newell, B. C., \& Gomez, R. (2015). Fotohistorias: Participatory Photography as a Methodology to Elicit the Life Experiences of Migrants. In Proceedings of HICSS 48 . Hawaii. Retrieved from http://papers.ssrn.com/abstract $=2482520$ 